\title{
Correlates of prepubertal bone mineral density in cystic fibrosis
}

\author{
R H M Haslam, D J Borovnicar, D B Stroud, B J G Strauss, J E Bines
}

\begin{abstract}
Aim-To examine early factors in bone mineral accretion in cystic fibrosis (CF). Methods-In 22 prepubertal children with CF and mild lung disease, the relation between total body bone mineral density (BMD) and measures of body composition, biochemistry, lung function, and physical activity was studied.

Results-There was a non-significant mild reduction in mean total body BMD. No relation was found between BMD and anthropometric indices, fat free soft tissue, degree of lung disease, degree of fat malabsorption, dietary energy intake, or level of physical activity. Significant impairments in physical growth were apparent in this population and were found to correlate with degree of lung disease.

Conclusion-A CF specific factor appears unlikely to be associated with the osteopenia commonly found in CF. Careful attention to general aspects of lifestyle and nutrition is recommended to maximise bone mineral accretion in this population. (Arch Dis Child 2001;85:166-171)
\end{abstract}

Keywords: bone mineral density; cystic fibrosis; children; nutrition; body composition

Department of

Paediatrics, Royal

Children's Hospital,

Melbourne, Australia

R H M Haslam

Department of

Gastroenterology and

Clinical Nutrition,

Royal Children's

Hospital, Melbourne,

Australia

J E Bines

Department of

Medicine, Monash

University, Melbourne,

Australia

B J G Strauss

Department of

Medical Physics,

Monash Medical

Centre, Melbourne,

Australia

D J Borovnicar

D B Stroud

Correspondence to: Dr R H M Haslam, Edward Wilson Building, Austin and

Repatriation Medical Centre, Locked Bag 25, Heidelberg,

3084, Victoria, Australia

rikhas@hotmail.com

Accepted 28 February 2001

With the dramatic improvements to life expectancy in cystic fibrosis (CF) over the past 25 years, attention has turned to complications which relate to older patients with CF. In particular, research has been directed towards factors which may maximise both survival and quality of life in the longer term. Osteopenia, commonly found in patients with $\mathrm{CF},{ }^{12}$ has been the subject of considerable research interest in the past decade, and exacts a considerable toll through fractures, back pain, and kyphosis. Numerous authors have addressed the many reasons for the observed reduction in bone mineral density (BMD); poor nutritional intake, pancreatic insufficiency, calcium and vitamin $\mathrm{D}$ malabsorption, reduced levels of physical activity, corticosteroid usage, pubertal delay, chronic respiratory acidosis, and elevations in osteoclast activating cytokines have all been considered. It is probable that the aetiology of osteopenia in CF is multifactorial; new avenues for preventive management should follow the elaboration of the role of these factors.

The concept of peak bone mass has been widely used in developing strategies for the prevention of osteoporosis in the general population. By maximising peak bone mass in adolescence or young adulthood, along with strategies to reduce the rate of bone mineral loss, fracture risk and development of thoracic kyphosis may be substantially reduced. Bone strength is principally determined by bone density and bone volume, and several studies have shown the correlation between low bone mass and increased risk of fracture at, for example, the femoral neck. Bone mass accumulation during growth in childhood and adolescence is thought to be under the influence of a number of factors such as body weight, Tanner stage, and a variety of specific risk factors. ${ }^{3-5}$ In $\mathrm{CF}$, the other factors, both disease specific and iatrogenic, noted above may also come into play.

In normal children, total body BMD increases with age in a curve which resembles that for linear growth. ${ }^{6}$ In puberty, there appear to be regional differences in bone mineral accretion. For example, the femur and spine have been found to undergo mineralisation at different rates. ${ }^{7}$ In $\mathrm{CF}$, it appears that bone mineralisation accretion begins to stray from normal developmental lines around the time of puberty. Failure to accrete bone mineral at an appropriate rate, as well as bone mineral loss have been considered. ${ }^{8}{ }^{9}$ Recent evidence has suggested that it is in fact inadequate accretion of bone mineral, rather than bone loss which plays the major role. ${ }^{10}$

Given that factors such as low body mass, gonadal dysfunction, and reduced physical activity have all been found to correlate with deficits in BMD, ${ }^{11}{ }^{12}$ there would appear to be significant therapeutic potential in characterising the prepubertal correlates of BMD in order to maximise eventual peak bone mass. In this study we have sought therefore to consider pertinent factors in early bone mineral status.

The current study forms a part of a wider cross sectional characterisation of body composition in a cohort of Australian children with $\mathrm{CF}$ and mild or moderate lung disease, which included pulmonary and gastrointestinal status, biochemical markers of body composition, direct and indirect measures of body composition, and analyses of dietary intake, fat malabsorption, and physical activity. It was hypothesised that, in these prepubertal children, fat free soft tissue (FFST) content, dietary energy intake, illness severity, fat malabsorption, linear growth, and physical activity would correlate significantly with total body BMD.

\section{Methods}

SUBJECTS

Children with mild symptoms of CF were selected for this study. All subjects were recruited from the Royal Children's Hospital 
Cystic Fibrosis Clinic. Diagnosis of CF had previously been confirmed by genotype, or raised sweat chloride. Patients were invited for inclusion if aged between 7.0 and 13.0 years, with prepubertal physical development, mild lung disease on the basis of physical examination, chest $x$ ray and spirometry, and were clinically stable at the time of study.

Subjects were excluded if they had shown a weight change in excess of $\pm 1.5 \mathrm{~kg}$ over the two months preceding the study, hospitalisation in the two months preceding the study, comorbidities likely to confound body composition measurement (for example, diabetes mellitus, clinical or biochemical evidence of liver disease, oedema), current use of drugs likely to confound body composition measurement (for example, use of corticosteroids or growth hormone for the preceding year, use of diuretics), or severe lung disease defined as forced expiratory volume in one second $\left(\mathrm{FEV}_{1}\right)$ less than $40 \%$ predicted for age, height, and gender.

Ethics approval was obtained from the human ethics committees of the Royal Children's Hospital and the Monash Medical Centre. Informed consent was signed by the subject and their parent or guardian.

CLINICAL ASSESSMENT

Anthropometry, clinical biochemistry, clinical asssessment of pubertal status, and body composition assessment by dual energy $x$ ray absorptiometry (DEXA) were performed within a four hour period at the Body Composition Laboratory at the Monash Medical Centre.

Anthropometric measurements were performed in accordance with the standards of Lohman and colleagues. ${ }^{13}$ Weight was assessed by digital scale, and height by stadiometer.

Pulmonary status was assessed by a thoracic physician within a 12 week period of the body composition assessment. This assessment included spirometry and determination of the Holzer score, which combines cough, sputum production, chest $x$ ray findings, and pulmonary function. ${ }^{14}$

A three day weighed food diary and stool collection were completed within two weeks of body composition analysis with the assistance of the subjects' parents or guardians. Nutritional content was analysed for the majority of foods using the Nutritionist III (Version 4) package (N Squared Computing, Salem, USA). Other foods not incorporated in the computer package were characterised by the Body Composition Laboratory's Monash Nutrient Analysis Program (Monash University, Melbourne, Australia), or by reference to food labels or food composition tables. ${ }^{15}$ The fat content of stools was assessed using the method of Van der Kamer and colleagues. ${ }^{16}$

A seven day diary and self report questionnaire were completed within two weeks of body composition analysis to assess weekly energy expenditure based on type and duration of physical activities. Activities were classified on the basis of the ratio of metabolic rate during the activity to resting metabolic rate. The scoring system of Ainsworth and colleagues ${ }^{17}$ was
Table 1 Clinical and body composition characteristics

\begin{tabular}{|c|c|c|c|}
\hline & $\begin{array}{l}\text { Total no. } \\
\text { subjects }\end{array}$ & Mean & Range \\
\hline $\mathrm{FEV}_{1}(\mathrm{l})$ & 22 & 1.579 & $0.64-2.71$ \\
\hline FVC (1) & 22 & 1.93 & $1.00-3.04$ \\
\hline Height $(\mathrm{cm})$ & 22 & 137.3 & $124.6-149.0$ \\
\hline Weight $(\mathrm{kg})$ & 22 & 30.13 & $23.3-36.4$ \\
\hline $\mathrm{BMI}\left(\mathrm{kg} / \mathrm{m}^{2}\right)$ & 22 & 15.90 & $13.58-17.66$ \\
\hline Energy intake (J/day) & 22 & 8301 & $4933-12249$ \\
\hline Physical activity (J/day) & 21 & 7879 & $6555-10275$ \\
\hline $\begin{array}{l}\text { Calcium intake } \\
\text { (mg/day) }\end{array}$ & 21 & 953 & $228-1646$ \\
\hline $\begin{array}{l}25(\mathrm{OH}) \text { vitamin } \mathrm{D} \\
\text { intake (IU/day) }\end{array}$ & 21 & 256 & $22-503$ \\
\hline $\begin{array}{l}\text { Total body BMD } \\
\left(\mathrm{g} / \mathrm{cm}^{2}\right)\end{array}$ & 22 & 0.888 & $0.785-1.019$ \\
\hline Total body BMC (g) & 22 & 1237 & $857-1786$ \\
\hline Total body FFST (g) & 22 & 24168 & $18178-30786$ \\
\hline$\%$ fat absorption & 21 & 82 & $29-97$ \\
\hline
\end{tabular}

used to grade activities on the basis of their intensity.

LABORATORY ASSESSMENT

Fasting venous blood samples were collected at the time of body composition assessment and analysed by standard methods for calcium, phosphorus, alkaline phosphatase, gamma glutaryl transferase and 25-hydroxyvitamin D, and sodium, potassium, chloride, urea, creatinine, bilirubin, and albumin.

BONE MINERAL AND FAT FREE SOFT TISSUE ASSESSMENT

Total body DEXA scans were performed using the Lunar absorptiometer (Lunar Corp., Madison, Wisconsin; software version 3.8). Scans were performed at medium scan speed requiring a 15 minute study period. The measurement precision for total body BMD and FFST content is reported to be $0.8 \%$ and $1.5 \%$ respectively. ${ }^{18}$ The effective dose by this method is $<0.01 \mathrm{mSv}$.

\section{STATISTICS}

Descriptive statistics, logarithmic transformations, and Pearson's and Spearman's correlations were performed using Stataquest 4 software package (Stata Corporation, Texas, 1996). Reference data from the US National Center for Health Statistics physical growth percentiles and the reference population of Lunar Corporation comprising 15000 children were used to assess anthropometric and total body BMD measurements of $\mathrm{CF}$ subjects on the basis of $\mathrm{z}$ scores and the one sampled $t$ test. The normal reference range of $\mathrm{z}$ scores was interpreted as -2 to +2 , and a two sided $p$ value less than 0.05 was considered significant. The chart was prepared using Microsoft Excel 97 SR-2.

\section{Results}

Twenty two children participated in the study (14 boys, age range 7.6-12.5 years). Table 1 shows selected clinical parameters. Their mean age was 10.2 years (boys: 9.9 years, girls: 10.7 years; SD 1.6). Nine children were homozygotic for the F508 gene. Tanner staging by clinical examination indicated 20 children at stage 1 , and two at stage 2 . 
Table 2 Correlates of total body BMD $\left(\mathrm{g} / \mathrm{cm}^{2}\right)$

\begin{tabular}{llll}
\hline & $\begin{array}{l}\text { Total no. } \\
\text { subjects }\end{array}$ & $\begin{array}{l}\text { Correlation } \\
\text { coefficient } \\
(R)\end{array}$ & p value \\
\hline Age (y) & 22 & -0.29 & 0.20 \\
FEV $_{1}(1 / \mathrm{s})$ & 22 & -0.02 & 0.92 \\
Serum calcium (mg/ml) & 21 & -0.27 & 0.22 \\
Serum phosphate (mg/ml) & 21 & -0.50 & 0.03 \\
Serum alkaline & 20 & 0.17 & 0.45 \\
$\quad$ phosphatase (IU/ml) & & & \\
Serum 25(OH) vitamin D & 13 & -0.25 & 0.41 \\
$\quad(\mathrm{nmol} / \mathrm{l})$ & & & \\
Energy intake (J/day) & 21 & 0.07 & 0.75 \\
Calcium intake (mg/day) & 21 & 0.16 & 0.49 \\
25(OH) vitamin D intake & 21 & 0.07 & 0.75 \\
$\quad(\mathrm{IU} /$ day) & & & \\
Physical activity (J/day) & 22 & 0.36 & 0.11 \\
DEXA FFST (g) & 22 & 0.15 & 0.50 \\
Height (cm) & 22 & 0.02 & 0.95 \\
Weight (kg) & 22 & 0.24 & 0.27 \\
BMI (kg/m $\left.{ }^{2}\right)$ & 22 & 0.40 & 0.07 \\
\hline
\end{tabular}

Table 3 Correlates of FEV $(\mathrm{l} / \mathrm{s})$

\begin{tabular}{llll}
\hline & $\begin{array}{l}\text { Total no. } \\
\text { subjects }\end{array}$ & $\begin{array}{l}\text { Correlation } \\
\text { coefficient }(R)\end{array}$ & p value \\
\hline $\begin{array}{l}\text { Energy intake (J/day) } \\
\text { Physical activity }\end{array}$ & 21 & 0.47 & 0.03 \\
$\quad 22$ & 0.42 & 0.06 \\
$\quad(\mathrm{~J} /$ day) & & & \\
$\begin{array}{l}\text { DEXA FFST (g) } \\
\text { Height (cm) }\end{array}$ & 22 & 0.71 & 0.0002 \\
Weight (kg) & 22 & 0.74 & 0.0001 \\
\hline
\end{tabular}

The study population, although young and with generally mild lung disease (see below), already showed impairments in anthropometric parameters of growth. Mean height for age $\mathrm{z}$ score for the population was -0.31 (SD 0.90; $\mathrm{p}=0.12)$. Mean weight for age $\mathrm{z}$ score was -0.56 (SD 0.82; $\mathrm{p}=0.0043$ ). Male and female subjects showed very similar values for mean height $(137.2 \mathrm{~cm}$ in boys; $137.4 \mathrm{~cm}$ in girls), weight (29.9 kg in boys; $30.55 \mathrm{~kg}$ in girls), and BMI (15.76 in boys; 16.14 in girls). Comorbid medical conditions were generally uncommon, with two cases of recurrent otitis media, one of moderate oesophageal stricture, and one of mild thoracic scoliosis. Twenty one subjects were receiving pancreatic enzyme replacement therapy and their mean percentage fat absorption on three day stool analysis was $80 \%$. One subject had normal pancreatic function. Nineteen subjects were receiving regular antibiotic therapy, and three subjects had received daily multivitamin preparations for the past three years. No patients were receiving specific vitamin $\mathrm{D}$ supplementation. One subject did not complete the three day weighed food diary,

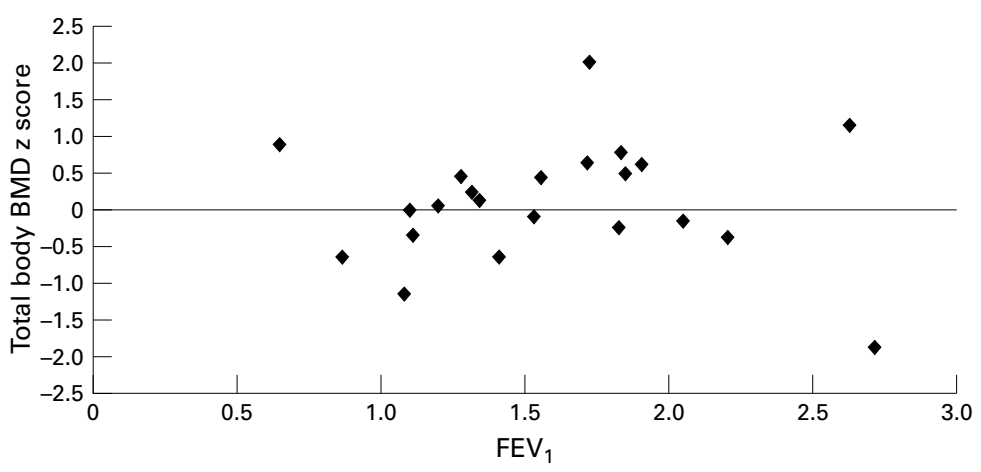

Figure 1 Relation of total body BMD (z score) to FEV . one subject did not complete the three day stool collection, and one subject refused venepuncture.

Dietary intake was variable within the study group (table 1). Only five of 21 children exceeded the recommended daily intake (RDI) for their age and gender for energy. ${ }^{19}$ In all the dietary indices shown, the boys had significantly higher intake; for example, mean daily vitamin D intake was $317 \mathrm{IU}$ in the boys and $133 \mathrm{IU}$ in the girls. Twelve subjects reported intake of calcium below that recommended for age, while only six had reported phosphorus intake below that recommended for age. In 16 subjects, daily intake of vitamin $\mathrm{D}$ was less than the RDI for age. ${ }^{20} \mathrm{~A}$ wide range of values was recorded for both energy intake and physical activity, reflecting major lifestyle variation among these children (table 1).

Serum sodium, potassium, chloride, urea and creatinine, calcium, and phosphate $(n=21)$ were within normal laboratory ranges in all patients. Serum $25(\mathrm{OH})$ vitamin D levels $(\mathrm{n}=13)$ were all within normal laboratory range $(28-165 \mathrm{nmol} / \mathrm{l})$. Twenty of 21 children showed normal liver function on biochemical assay, with moderate elevations in alkaline phosphatase and gamma glutaryl transferase levels in one subject.

Mean total body BMD for age $\mathrm{z}$ score was -0.148 (range -1.92 to +1.98 ; SD 0.72 ; $\mathrm{p}=0.35)$. BMD was not found to correlate with most variables in table 2 in contrast to the relations hypothesised in this study. In particular, no significant relation was found between BMD z score and $\mathrm{FEV}_{1}$ expressed either as a raw score (fig 1) or a percentage of predicted for age and gender. The relations between BMD and physical activity and BMI approached significance, and a weak negative relation between serum phosphate and BMD was shown. No evidence of significant associations between total body bone mineral content (BMC) and the parameters in table 2 was found (data not shown). Serum phosphate had almost no relation with dietary phosphorus (Pearson's $r=-0.086$ ).

Lung disease in the study population was assessed by Holzer score to be mild in 16 subjects, and moderate in six subjects. One subject had been admitted on two or more occasions in the preceding 12 months for management of respiratory disease. Twelve patients had sputum colonised by Pseudomonas aeruginosa. Mean $\mathrm{FEV}_{1}$ expressed as a percentage of that predicted for age and gender was $81.3 \%$ (SD 20.7 ; range $44.4-127.2 \%$; $p<0.001$, difference from $100 \%$ by one sample $t$ test). Forced vital capacity (FVC) as a percentage of that predicted for age and gender ranged from $61.7 \%$ to $112.9 \%$ (mean 88.33 , SD 15.7 ; $\mathrm{p}<0.01$, difference from $100 \%$ by one sample $t$ test). Table 3 summarises the relations between lung function, as measured by $\mathrm{FEV}_{1}$, and parameters of physical growth and energy balance. There is a strong positive correlation between FFST and $\mathrm{FEV}_{1}$, which suggests a relation between muscle mass and lung function. Similarly, a positive correlation between energy intake and $\mathrm{FEV}_{1}$ implies that energy 
balance may impact on respiratory status in an independent fashion.

\section{Discussion}

The population in this study represents an unselected clinic sample of prepubertal children with $\mathrm{CF}$ and mild lung disease. A number of factors which could be expected to affect bone mineral status in other studies have been considered in recruiting this population. Firstly, a prepubertal population was selected to permit study of a group of children with $\mathrm{CF}$ before the influence of the normal (or frequently delayed) pubertal growth spurt. Pubertal delay itself is a significant risk factor for osteopenia. ${ }^{1}$ In addition physical activity and compliance with management is often found to become more variable with the onset of adolescence, thereby complicating the cross sectional analysis of a variety of factors in chronic illnesses such as CF. Secondly, a population without severe lung disease was chosen, as earlier studies have identified substantial differences in body composition and nutritional status in this group which are less pertinent to more well nourished patients. Similarly, a number of exclusion criteria were included to avoid potential confounders such as growth hormone or systemic corticosteroid use, clinically significant comorbidities such as liver disease or pancreatitis, or recent significant illness requiring hospitalisation. It was anticipated that these criteria would provide a relatively homogeneous group in which to characterise factors relevant to body composition analysis in children with CF but with only mild lung disease.

Normal bone mineralisation requires adequate raw materials: nutrition, protein for osteoid formation, and calcium and phosphorus for calcification; weight bearing and muscle use; and appropriate hormonal modulation. In $\mathrm{CF}$ there are a number of other factors to consider: chronic lung infection, iatrogenic effects, and fat soluble vitamin malabsorption, for example. Numerous authors have identified reduced bone mineral in adults with $\mathrm{CF} .^{1921}$ Bone mineralisation studies in prepubertal children with CF have, however, been less consistent. Gibbens and colleagues, ${ }^{2}$ using quantitative computed tomography, and Bhudikanok and colleagues, ${ }^{22}$ using dual energy radiographic absorptiometry have shown demineralisation in this population, in contrast to the findings of Solomons and colleagues ${ }^{23}$ and Mischler and colleagues. ${ }^{24}$ The present study found total body BMD to be distributed in the normal range. Furthermore, BMD was not predicted by physical activity, dietary energy intake, dietary calcium, or vitamin $\mathrm{D}$ intake, or by height, weight, or degree of lung disease.

A number of important findings are evident in the data of this study which have both clinical and research implications. As a group, these prepubertal children with mild but significant CF lung disease exhibit no reduction in total body BMD. This does not support the hypothesis that there is a disease specific process operating on bone or vitamin D metabolism and responsible for the osteopenia observed in older patients with CF. While there appears to be growing consensus that osteopenia is widespread in $\mathrm{CF}$, the evidence from this study suggests that it is not a typical finding in younger, more mildly affected children. Researchers in this field have in contrast failed to reach agreement on the significance of a variety of factors in bone mineral accretion during childhood and adolescence. Many of these factors have been analysed in the present study, such as severity of lung disease, level of physical activity, and FFST content. Notwithstanding the limitations to attributing causality from cross sectional studies, these data do not suggest that a major role will be found from the variables above in research and clinical practice aimed at the risk of osteopenia in the developing child with CF. Attention to general aspects of nutrition, management of lung disease, and lifestyle may be the best approach to optimising peak bone mass at this age.

Lung disease, as measured by $\mathrm{FEV}_{1}$ or FVC, was found to correlate with anthropometric measures of body composition such as height and weight, body composition (in particular the FFST component), and with indices of dietary energy intake and physical activity. The comparatively weak relation observed between physical activity and $\mathrm{FEV}_{1}$ suggests that physical exertion is not substantially limited by lung disease in this population. As a group, then, these children showed the characteristic deterioration in lung function, but in the absence of any significant reduction in BMD.

Conflicting findings have been obtained on the issue of physical activity in bone mineralisation; Stamp and Geddes ${ }^{25}$ highlighted its importance, while others have found a limited relation ${ }^{22}$ or none. ${ }^{4}$ Slemenda and colleagues, ${ }^{7}$ using a parent and child questionnaire to assess physical activity, found that prepubertal children in the uppermost quartile of weight bearing physical activity had rates of bone mineralisation $4-7 \%$ greater than those in the lowest quartile. Methodological differences explain some of this variance of results. Physical activity may not have correlated in this study because weight bearing activities were not separately analysed. ${ }^{12}$ The data from the current study suggest that the association is not strong in the prepubertal child with CF. The presence of a control group of normal children would have allowed an assessment of relative reductions in physical exertion in the $\mathrm{CF}$ children.

Height has been shown to be closely correlated with bone mass accumulation in healthy children at the heights represented in this study. ${ }^{3}$ Beyond these levels, linear growth velocity and bone mass accumulation tend to diverge, suggesting that there are other factors coming into play. In adolescents and more severely affected children with CF in particular, there are complex and often severe influences on linear growth and increasing body mass. Our study suggests that in mildly affected children there may be subtly interacting factors affecting bone mineral accretion which do not appreciably alter the measurement of bone mineral status. 
Earlier studies have indicated an association between FFST and BMD in normal children. Faulkner and colleagues ${ }^{26}$ studied body composition in healthy children and adolescents and found a significant correlation between total body BMD and FFST in boys and girls. Ogle and colleagues ${ }^{27}$ and Gutin and colleagues ${ }^{28}$ identified corresponding associations between lean tissue mass (fat free body mass) and FFST, and total body BMC. In adults with $\mathrm{CF}$, Rochat and colleagues ${ }^{29}$ found a relation between deficits in BMC and FFST and proposed that the bone mass deficit observed reflected general malnutrition, rather than a specific problem in bone metabolism in CF. This result has been replicated in a small group of children and adolescents by Salamoni and colleagues $^{30}$; in particular, the correlation between fat free mass and BMC applied even in the youngest of the cohort, who ranged upwards in age from 6.6 years. The lack of correlation in our study between BMD or BMC and FFST was therefore unexpected, but could be caused by methodological differences including the more defined age range in the present study, or nutritional differences in the populations as reflected by a mean dietary energy intake $30 \%$ higher in the Swiss study. ${ }^{29}$ The current data suggest that a significant correlation between FFST and bone mineral status is unlikely to be found among prepubertal children with only mild lung disease.

Dietary energy needs are increased in $\mathrm{CF}^{31}$; Gibbens and colleagues ${ }^{2}$ found poor nutrition to correlate with low BMD. It may be, however, that the increase in energy needs in CF over and above those required for normal growth become clinically evident through deteriorating nutritional and bone mineral status only in adolescence. This may apply for specific minerals and nutrients also. Dietary calcium intake did not correlate with BMD, a finding which supports earlier results from Bhudikanok and colleagues, ${ }^{22}$ Katzman and colleagues, ${ }^{4}$ and Grey and colleagues. ${ }^{9}$ There is unlikely to be a role for dietary supplementation with calcium above recommended levels for healthy children.

This study was limited by several factors. The select population did not allow a cohort size with the statistical power to assess small trends among the many pertinent factors. The absence of a finding of several major influences on BMD in this cohort suggests that either these factors are not important in bone accretion, or the need for more subjects (such as a multicentre trial would permit) in searching for more subtle determinants. The absence of a control group prevented direct comparison with a local population of such elements as physical activity, dietary vitamin $\mathrm{D}$ and energy intake, and BMI. The findings from this study, while of specific relevance to the many children with $\mathrm{CF}$ who have mild lung disease, cannot be generalised to children with more severe lung disease. Longitudinal follow up should yield valuable data on body composition changes as these children undergo puberty, and on the course of their disease.
Routine clinical management in prepubertal children with CF will continue to include nutritional guidance and support, encouragement of regular physical activity, and control of lung disease. As research turns towards aggressive treatment of osteopenia in adults with CF including antiresorptive agents, there remains much to be understood in its prevention in childhood. Future research will need to address the need for large sample, cross sectional work of this kind, longitudinal studies through childhood and adolescence, and the effectiveness of dietary and lifestyle interventions in adolescents. It appears currently that the most effective considerations in childhood to further skeletal health will involve advocating an active, but largely normal, lifestyle.

The authors wish to thank Dr CF Robertson for his constructive suggestions in planning this research with the Department of Thoracic Medicine at the Royal Children's Hospital, and Dr Jose Gutierrez for the use of his Seven Day Physical Activity Questionnaire and Diary.

1 Bachrach LK, Loutit CW, Moss RB, Marcus R. Osteopenia in adults with cystic fibrosis. Am f Med 1994;96:27-34.

Gibbens DT, Gilsanz V, Boechat MI, et al. Osteoporosis in cystic fibrosis. F Pediatr 1988;113:295-300.

3 Bonjour J-P, Theintz G, Buchs B, et al. Critical years and Bonjour J-P, Theintz $\mathrm{G}$, Buchs $\mathrm{B}$, et al. Critical years and
stages of puberty for spinal and femoral bone mass accumulation during adolescence. F Clin Endocrinol Metab 1991;73:555-63.

4 Katzman DK, Bachrach LK, Carter DR, Marcus R. Clinical and anthropometric correlates of bone mineral acquisition in healthy adolescent girls. F Clin Endocrinol Metab 1991;73:1332-9.

5 Southard RN, Morris JD, Mahan JD, et al. Bone mass in healthy children: measurement with quantitative DXA. Radiology 1991;179:735-8

6 Glastre C, Braillon P, David L, et al. Measurement of bone mineral content of the lumbar spine by dual energy $\mathrm{x}$ ray absorptiometry in normal children: correlations with growth parameters. F Clin Endocrinol Metab 1990;70: 1330-3.

7 Slemenda CW, Reister TK, Hui SL, et al. Influences on skeletal mineralization in children and adolescents: evidence for varying effects of sexual maturation and physical maturity. F Pediatr 1994;125:201-7.

8 Baroncelli GI, De Luca F, Magazzu G, et al. Bone demineralization in cystic fibrosis: evidence of imbalance between bone formation and degradation. Pediatr Res 1997;41:397403 .

9 Grey AB, Ames RW, Matthews RD, Reid IR. Bone mineral density and body composition in adult patients with cystic fibrosis. Thorax 1993;48:589-93.

10 Bhudhikanok GS, Wang M-C, Marcus R, et al. Bone acquisition and loss in children and adults with cystic fibrosis: a longitudinal study. F Pediatr 1998;133:18-27.

11 Boot AM, de Ridder MA, Pols HA, et al. Bone mineral density in children and adolescents: relation to puberty, calcium intake, and physical activity. $\mathcal{F}$ Clin Endocrinol Metab 1997;82:57-62.

12 Slemenda CW, Miller JZ, Hui SL, et al. Role of physical activity in the development of skeletal mass in children. $\mathcal{F}$ Bone Miner Res 1991;6:1227-33.

13 Lohman TG, Roche AF, Martorell R, eds. Anthropometric standardisation reference manual. Illinois: Human Kinetics, 1988.

14 Holzer FJ, Olinsky A, Phelan PD. Variability of airways, hyper-activity and allergy in cystic fibrosis. Arch Dis Child 1981;56:455-9.

15 Rogers J. What food is that? And how healthy is it? Adelaide: Griffin Press, 1990.

16 Van der Kamer JH, Bokkel Huinink H, Weyers HA. Rapid method for the determination of fat in faeces. $\mathcal{F}$ Biol Chem 1949;177:347-55.

17 Ainsworth BE, Haskell WL, Leon AS, et al. Compendium of physical activities: classification of energy costs of human activities. Med Sci Sports Exerc 1993;25:71-80.

18 Mazess RB, Barden HS, Bisek JP, Hanson J. Dual-energy $\mathrm{x}$-ray absorptiometry for the total-body and regional bonemineral and soft-tissue composition. Am F Clin Nutr 1990; 51:1106-12.

19 National Research Council. Recommended dietary allowances, 10th edn. Washington, DC: National Academic Press, 1989.

20 Department of Health and Social Security. Recommended daily amounts of food, energy, and nutrients for groups of people in the United Kingdom. Report on Health and Social in the United Kingdom. Report on Heatr.

21 Hahn TJ, Squires AE, Halstead LR, Strominger DB. Reduced serum 25-hydroxyvitamin D concentration and 
disordered mineral metabolism in patients with cystic fibrosis. 7 Pediatr 1979;94:38-42.

22 Bhudhikanok GS, Lim J, Marcus R, et al. Correlates of osteopenia in patients with cystic fibrosis. Pediatrics 1996:97:103-11.

23 Solomons NW, Wagonfeld JB, Rieger C, et al. Some biochemical indices of nutrition in treated cystic fibrosis patients. Am F Dis Child 1981;34:462-74.

24 Mischler EH, Chesney J, Chesney RW, Mazess RB. Demineralization in cystic fibrosis. Am $\mathcal{f}$ Dis Child 1979;133:632-5.

25 Stamp TCB, Geddes DM. Osteoporosis and cystic fibrosis [editorial]. Thorax 1993;48:585-6.

26 Faulkner RA, Bailey DA, Drinkwater DT, et al. Regional and total body bone mineral content, bone mineral density, and total body tissue composition in children 8-16 years of age. Calcif Tissue Int 1993;53:7-12.
27 Ogle GD, Allen JR, Humphries IR, et al. Body-composition assessment by dual-energy x-ray absorptiometry in subjects aged 4-26 y. Am f Clin Nutr 1995;61:746-53.

28 Gutin B, Litaker M, Islam S, et al. Body-composition measurement in 9-11-y-old children by dual-energy X-ray absorptiometry, skinfold-thickness measurements, and bioimpedance analysis. Am f Clin Nutr 1996;63:287-92.

29 Rochat T, Slosman DO, Pichard C, Belli DC. Body composition analysis in dual-energy x-ray absorptiometry in adults with cystic fibrosis. Chest 1994;106:800-5.

30 Salamoni F, Roulet M, Gudinchet F, et al. Bone mineral content in cystic fibrosis patients: correlation with fat-free mass. Arch Dis Child 1996;74:314-18.

31 Parsons HG, Beaudry P, Dumas A, Pencharz PB. Energy needs and growth in children with cystic fibrosis. F Pediatr Gastroenterol Nutr 1983;2:44-9.

\title{
1st Asia Pacific Forum on Quality Improvement in Health Care
}

\author{
Three day conference
}

\section{Wednesday 19 to Friday 21 September 2001 Sydney, Australia}

We are delighted to announce this forthcoming conference in Sydney. Delegate enquiries are welcome.

The themes of the Forum are:

- Improving patient safety

- Leadership for improvement

- Consumers driving change

- Building capacity for change: measurement, education and human resources

- The context: incentives and barriers for change

- Improving health systems

- The evidence and scientific basis for quality improvement.

Presented to you by the BMJ Publishing Group (London, UK) and Institute for Healthcare Improvement (Boston, USA), with the support of the the Commonwealth Department of Health and Aged Care (Australia), Safety and Quality Council (Australia), NSW Health (Australia), and Ministry of Health (New Zealand).

For more information contact: quality@bma.org.uk or fax +44 (0)2073836869 